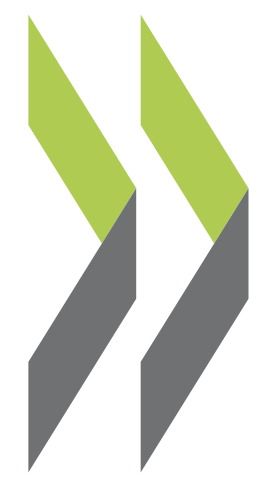

PEB Exchange, Programme on Educational Building 1999/01

\title{
The Netherlands' School Building Prize
}




\section{THE NETHERLAN D S' SCHOOL BUILDING PRIZE}

The School Building Prize has been awarded every two years since 1992 to Dutch school boards that have proved able to embracenew directionsin school building design while keeping within their available budget The Prize, which has drawn acclaim for the development of high quality educational architecture in the Netherlands, provides publicity for successful projects so that other schools can benefit from the designs and information. Associated with this prize are the Dutch Ministry of Education, Culture and Sciences; the Ministry of Housing, Urban and Rural Planning, and Environmental Management; and the Association of Dutch Municipalities.

For the 1998 award all school governing bodies that had invested at least 500000 Guilders to build or drastical ly expand or renovate an elementary school between 1994 and 1997 were invited to participate. The competition was reserved for primary schools, as the previous prize had been given to an adulteducation institution. The jury included architects, professors, government representatives and a town planner. They evaluated the projectsaccording to the following criteria:

- process and project the selection process for an architect and consultants; the client's ability to build a balanced team and manage the project; the layout as a whole and the variety of spaces available to the pupil; the possibility for multiple uses of the building for educational and other purposes at present and in the future;

- architectural interpretation: the interplay between elements such asstructure, space, lightand choice of materials and their influence on the building's atmosphereand quality of the facilities; theextent to which the architect succeeded in involving the client in the design process;

- construction: the use of durable materialsin order to ensure the maximum life of the building;

- adaptation to town planning and the landscape: the building's spatial integration into its neighbourhood as well as a clear delineation between the school and its surroundings;

- qual ity and cost: the costs incurred in relation to the quality of the building and the available budget.
First prize winner: British School in The Hague

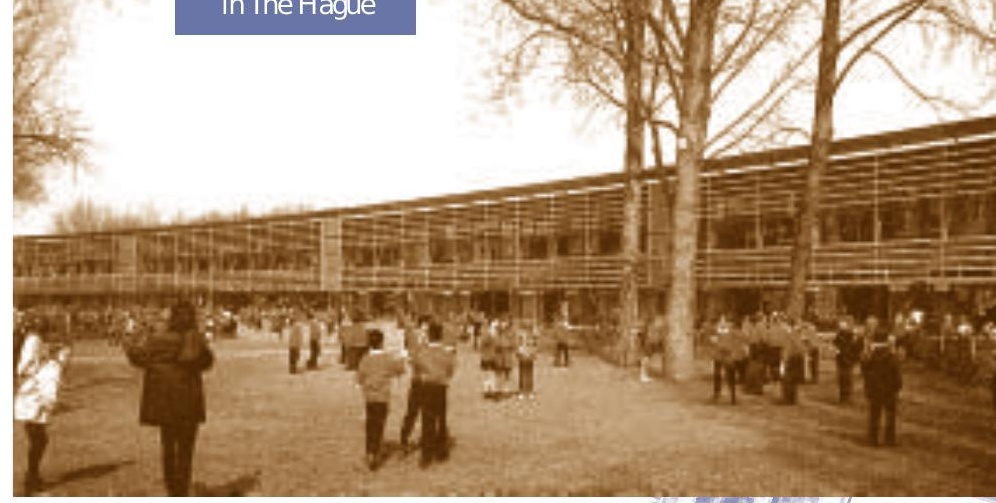

\section{First prize}

The 1998 School Building Prize was awarded to the British School in The Hague, an elementaryand junior secondary school. Although the school was built according to Dutch building regulations by a Dutch architect and construction company, the school's goveming body is not subject to the Dutch decision-making procedures for educational construction. This perhaps gave the British School more freedom to manoeuvre, but its construction costs, Gld 11241 955, were considered comparable to those of the other entries.

The jury found the school to be remarkably well adapted to its surroundings. The building is placed on a site with a previously existing sports hall and garden, and the garden is harmoniously incorporated into the school's landscaping. However with regard to its neighbourhood, the school occupies an isolated position.

The school building consists of two main parts, a rectangular section and a curved one, each with its own functional and architectural style. The classrooms are situated in the curved section overlooking the garden, and the rectangular area contains all of the other functions. An area uniting the two parts of the construction forms a spacious hallway with a mezzanine from which student circulation is fully observable.

It is a genuinely "green" building constructed of durable materials. Wood, glass, metal and concrete are visible in their natural state and are applied in an environmentally-friendly manner. Colour has been added only here and there.

The building makes use of natural climate regulation: cooling takes place by means of a sophisticated air 
British School in The Hague

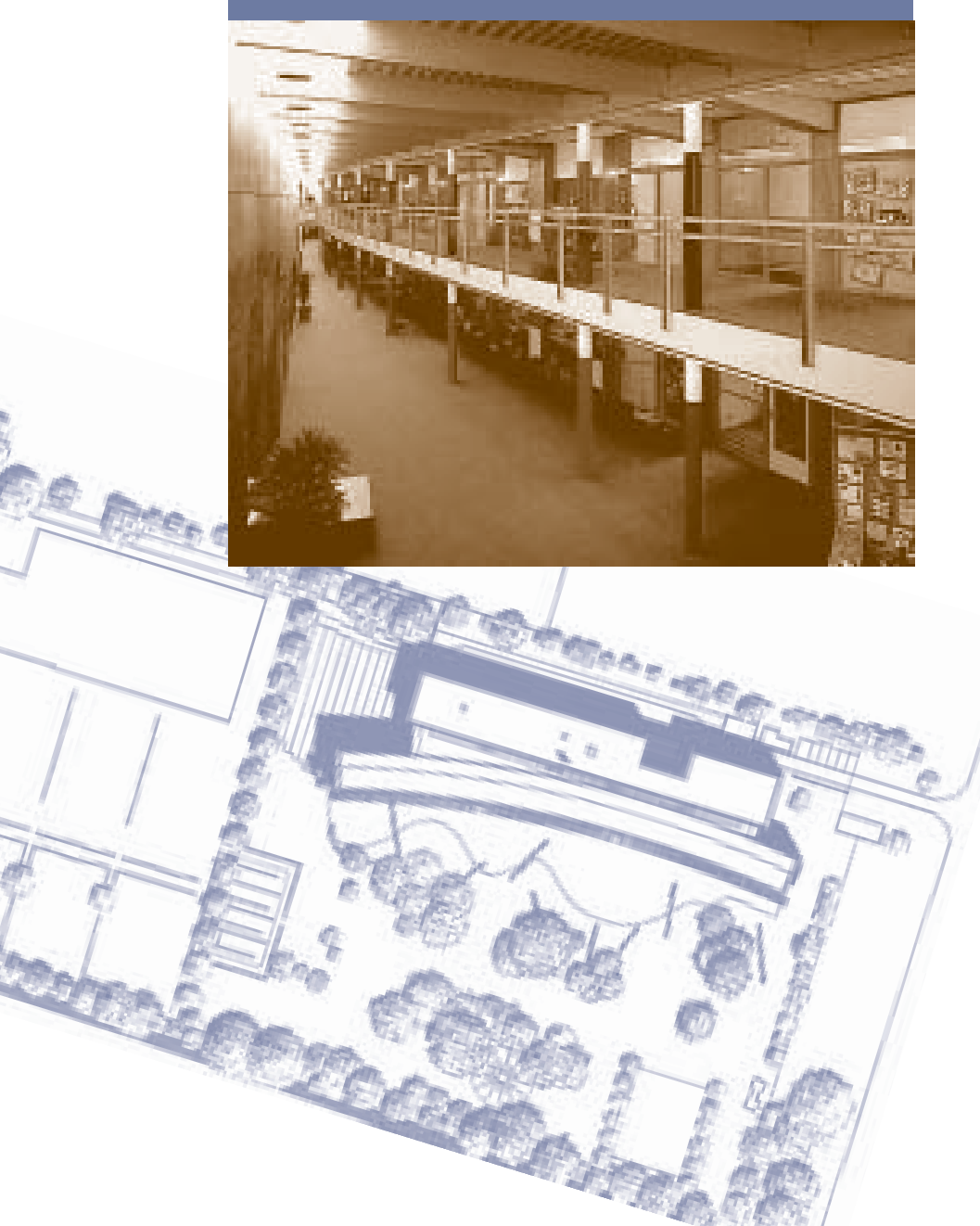

circulation system involving the "chimney effect" created by operable skylights in the central hallway. Because of this system, in place of drop ceilings, ceiling strips were applied where needed, taking maximum advantage of the thermal capacity of the exposed concrete.

The temperature can be regulated in each area separately; only the skylightsare operated centrally. The garden side of the building benefits from a southern exposure; in the winter sunlight enters through the aluminium slats of an external structure, which, in the summer, can be closed to deflect the sun's heat.

The building exudes a pleasant atmosphere which is reinforced by good acoustics. The openness of the construction al lows a sufficient view of each area for the children to situate themselves, and in spite of the buil ding's size - $6187 \mathrm{~m}^{2}$ - it does not give an impression of sheer mass.

It was clear to the jury that discussion between the architect and client led to the project's enhancement.

\section{Honourable mentions}

One of two honourable mentions was given to a Montessori elementary school, De Petteflet, in Tilburg. It was built at a cost of GId 3485000 with a grosssurface area of $1750 \mathrm{~m}^{2}$. The school's design is based on the three primary shapes that play an important role in Montessori teaching:

- the circle - created by the cylindrical tower that houses the staff areas;

- the triangle - represented by the building that contains most of the classrooms, those for the first years on the ground floor and the highest years on top;

- the square - formed by the section containing classrooms for the intermediate grades and indoor play areas.

The jury found the basic idea of the geometric shapes to be effective though somewhat contrived in places. Each of these sections has its own colour scheme and construction materials. The natural colours of the materials are exposed, making them easily recognisable by the children.

There are individual study spaces both inside and outside the classrooms, including study areas in the window sills for the older pupils. The youngest pupils have their own playground next to their classrooms.

The school is located in a town planning zone between different neighbourhoods. The area is characterised primarily by industrial buildings and sports fields and is separated from the residential area by roads.

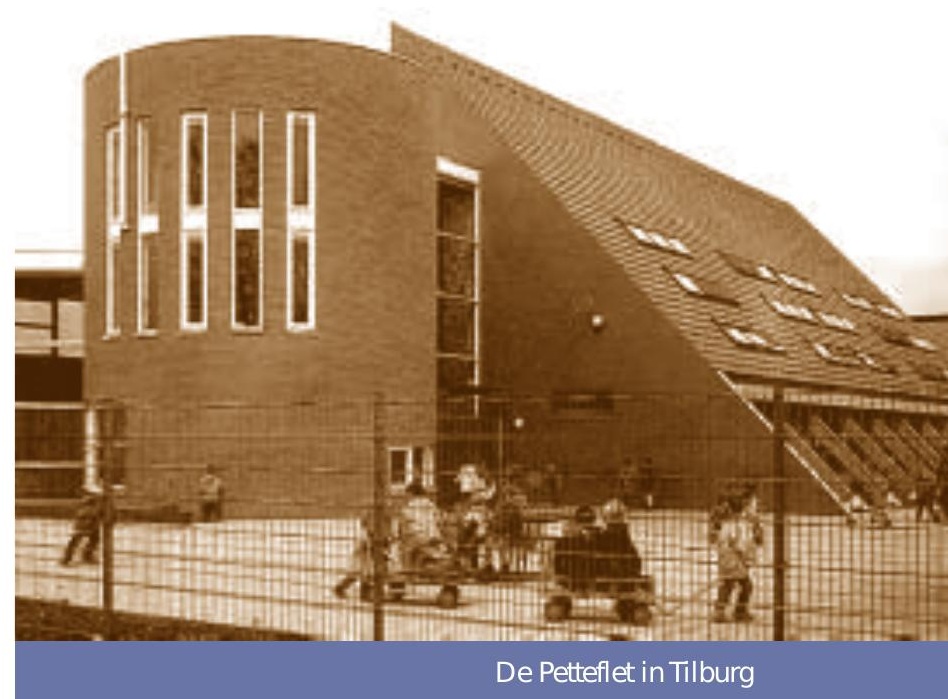


Again the architectural inspiration and the educational vision provided by the client were demonstrably united through constructive dial ogue.

A second honourable mention went to the primary school Het Spectrum, in Almere. It has a gross surface area of $2520 \mathrm{~m}^{2}$ and cost Gld 4600000 .

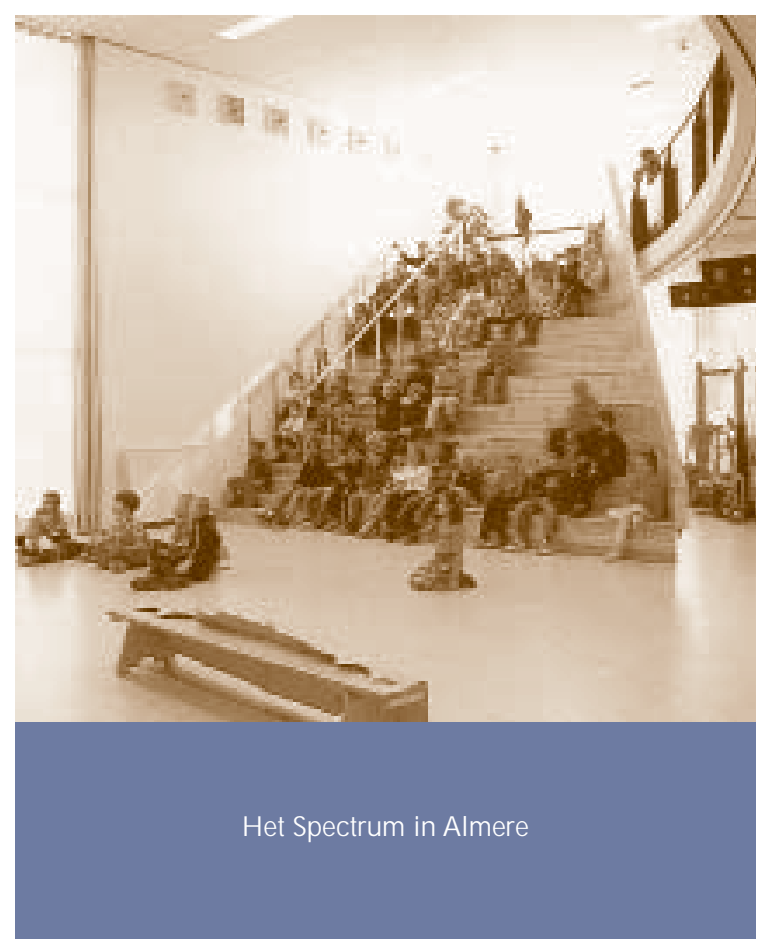

The school offers a clear structure and a spaciousness that the jury felt would have a lasting effect on the children. It houses a wide variety of spaces, with each classroom being a different shape. Like the De Petteflet school, classrooms for the first, middle and upper grades are grouped separately, each with a unique colour scheme. There are many cheerful elements to the school, such as a beautiful playroom and the communal area's creative "theatre wall". It was apparent to the jury that the client gave clear direction in the construction process and that the architect was sincerely concemed with reflecting the world of children, which led to a playful, exciting and flexible building.

\section{General findings of the jury}

Many of the 41 participating schools were found to have too lightweight a construction, requiring extra heating, cooling and ventilation to correct the internal climate and therefore raising operating costs. The jury reported that in most designs, information and communication technology as well as facilities for new teaching methods did not receive sufficient attention. The school playground was also often neglected; the result is that attractive schools are situated in poor settings and lack a clear delineation between the school grounds and their surroundings. Other common errors related to staircases designed with steps too high or built of steel, making inevitable falls more dangerous.

Theart of designing a school is to create an environment whose structure, visual stimulants and acoustics contribute to the harmonious development of the pupils. As primary education increasingly encourages children to independently explore their surroundings, buildings should provide freedom of movement inside and outside the classrooms, sufficient individual study spaces where children feel at ease and additional areas for a variety of activities.

It is important that prior to the design process the consultants, architects and client agree on the main needs. Then each party should evaluate, and if necessary re-adjust, the project from the point of view of his or her own competence. While the architect is responsible for the structural quality of the building, the educational programme of the school must remain the highest priority. Its reflection in a building's design requires conscious detailing of teaching styles, work methods and the educational situations that the school wishes to create.

Financial riskscan be reduced by designing flexible buildings, which increase the possibilities for other uses (while too much flexibility should be avoided as it can lead to anonymity and a loss of the characteristic school identity).

The jury concluded that those investing in the future would be well advised to demonstrate willingness to devote the extra financing which is often required to construct well-conceived school buildings.

A 48-page book in English and Dutch gives full details of the award process and provides photographs and plans of the nine finalist schools. Copies of "School Building Prize 1998" are available from:

ICS Adviseurs

P.O. Box 282

2800 AG Gouda, Netherlands

Tel.: 31182575200

Fax: 31182575201. 